\title{
Socioeconomic inequalities in the access to health services: a population-based study in Southern Brazil
}

\author{
Desigualdades socioeconômicas no acesso aos serviços de saúde: \\ um estudo de base populacional no sul do Brasil
}

Andrea Wendt (https://orcid.org/0000-0002-4640-2254) ${ }^{1}$
Luana Patrícia Marmitt (https://orcid.org/0000-0003-0526-7954) ${ }^{2}$
Bruno P. Nunes (https://orcid.org/0000-0002-4496-4122) ${ }^{1}$
Samuel C. Dumith (https://orcid.org/0000-0002-5994-735X) ${ }^{3}$
Inácio Crochemore-Silva (https://orcid.org/0000-0001-5390-8360) ${ }^{1}$

${ }^{1}$ Programa de Pós-

Graduação em

Epidemiologia,

Universidade Federal

de Pelotas. R. Marechal

Deodoro, $1.160,3^{\circ}$ andar.

96020-220 Pelotas RS Brasil.

andreatwendt@gmail.com

${ }^{2}$ Programa de Pós-

Graduação Stricto Sensu

em Biociências e Saúde,

Universidade do Oeste de

Santa Catarina. Joaçaba SC

Brasil.

${ }^{3}$ Programa de Pós-

Graduação em Saúde

Pública e em Ciências da

Saúde, Universidade Federal

do Rio Grande. Rio Grande

RS Brasil.

\begin{abstract}
This article aims to measure socioeconomic inequalities regarding access to health services, contact with health professionals, and specific health interventions. This was a cross-sectional population-based study with individuals aged 18 years or older, living in the city of Rio Grande. The outcomes were the following: Family Health Strategy (FHS) coverage; having a health insurance plan; receiving a visit of a community health worker; medical consultation; dental consultation; dietary counseling; having a class with a physical education professional; flu vaccination; mammography, cytopathological and prostate exams. Relative and absolute measures were used to assess inequalities in the distribution of the outcomes. There was a response rate of $91 \%$ (1,300 adults were interviewed). Coverage indicators ranged from $16.1 \%$, for having a class with a physical education professional, to $80.0 \%$ for medical consultation. FHS coverage and visit of a community health agent presented higher proportions among the poorest while outcomes regarding contact with health professionals, screening exams and flu vaccine were more prevalent among richest group. We observed low coverage levels of access to health services and professionals in addition to marked socioeconomic inequalities.

Key words Health services, Health inequalities, Socio-economic
\end{abstract}

Resumo $O$ objetivo deste artigo é mensurar desigualdades socioeconômicas no acesso a serviços de saúde, no contato com profissionais e em intervenções específicas. Estudo transversal de base populacional com indivíduos (18 anos ou mais) vivendo em Rio Grande. Os desfechos mensurados foram: cobertura da Estratégia de Saúde da Família (ESF), plano de saúde, visita do agente comunitário de saúde, consulta médica, consulta com dentista, aconselhamento nutricional, aula com professor de educação física, vacina da gripe, mamografia, exames citopatológico e de próstata. Medidas de desigualdade absolutas e relativas foram utilizadas para avaliar a distribuição dos desfechos. A taxa de resposta foi de $91 \%$ (1.300 adultos entrevistados). A cobertura dos indicadores variou de $16,1 \%$, para ter aula com professor de educação física, a 80,0\%, para consulta médica. Cobertura de ESF e visita do agente comunitário de saúde apresentaram maior proporções entre os mais pobres, enquanto desfechos de contato com profissionais de saúde, exames de rastreamento e vacina da gripe foram mais prevalentes entre os mais ricos. Foram observadas baixas coberturas de acesso aos serviços e contato com profissionais, bem como desigualdades sociodemográficas importantes.

Palavras-chave Serviços de saúde, Desigualdades, Socioeconômico 


\section{Introduction}

Socioeconomic inequalities in Brazil are a historical problem ${ }^{1}$. Even with a couple of decades with significant growth, disparities in income distribution remained, resulting in attenuated but persistent health inequalities ${ }^{2}$. In addition, wealth inequalities are also responsible for altering the health profile of the population ${ }^{3}$, with substantial differences in health-related behaviors and outcomes observed among population groups, and in general, more significant difficulties to access health care are observed among the poor ${ }^{2,4.5}$.

Universality is one of the fundamental principles of the Brazilian Unified Health System (Sistema Único de Saúde - SUS). It determines that access to actions and services must be guaranteed to all people, without discrimination ${ }^{6}$. Many programs and strategies have been created over time to guarantee this access to health. The most important was the Family Health Program (FHP), created in 1994, to allow teams of doctors, nurses, and community health workers to work in strategic locations in the country ${ }^{7}$. Despite the created strategies and the relative growth of the public sector, and mainly the subsidized growth of the country's private services, the persistence of inequalities imposes a need to identify vulnerable groups. The prevalence of health care for specific groups may differ from national averages, with vulnerable groups showing results that can be both worse and very distant from other groups ${ }^{4,5}$.

Previous studies in Brazil have shown this perspective of inequality at the national level ${ }^{4}$. A study with a sample from the National Health Survey carried out in 2013 found lower access to health services among the poorest individuals and young adults ${ }^{8}$. In terms of changes over time, a study using data from National Households Sample Surveys (Pesquisa Nacional de Saúde PNAD) assessed whether the participants visited a doctor or dentist. It also assessed whether they had been hospitalized in the last 12 months and whether they had sought health care in the last two weeks. A decrease in inequalities was observed for all outcomes between 1998 and 2008. However, a persistent difference between the poorest and the richest groups was observed ${ }^{9}$. Regarding prevalence of reproductive and maternal interventions, there is also evidence regarding the relevance of implementing SUS as a strategy for reducing inequalities across the time ${ }^{10,11}$.

In this context, it is possible to assume that a substantial part of the social disparities for morbimortality results from unequal access to health care $^{12}$. Identifying health inequalities and assessing their magnitude is essential to ensure universal access to health, quality of life, and social well-being, and develop strategies to decrease social injustices. Although some evidence at the national level is available to understand changes over time and the current scenario of socioeconomic health inequalities, monitored at the local level, are still required to help planning efficient strategies to improve public system process ${ }^{11}$. Furthermore, Brazil is a vast country with different characteristics across the cities. Our study is carried in a medium-sized Southern city of the country and understanding how inequalities behave in small cities may help to promote health in this context. Thus, this study aims to measure socioeconomic inequalities in health services, contact with health professionals and specific health interventions using a population-based sample of adults from a city in Southern Brazil.

\section{Methods}

This was a cross-sectional population-based study with individuals aged 18 years or older, living in the city of Rio Grande, Southern Brazil. Rio Grande has about 200 thousand inhabitants, with $96 \%$ of them residing in the urban area. This study is part of a larger project entitled "Health of Population of Rio Grande"13, which aimed to investigate several health-related behaviors and some chronic diseases. The research protocol was approved by the Ethics Committee of Research on Health from the Federal University of Rio Grande, under process number 20/2016.

The sampling process was carried out in two stages: first, we systematically selected 72 census tracts (a quarter of all in the urban zone), and after we selected an average of 10 households with probability proportional to the tract size, totaling 720 households. Because the mean estimated number of individuals aged 18 years or more per household was two, we expected to find approximately 1,440 individuals. All individuals aged 18 years or more were considered eligible for study ${ }^{13}$.

Data was collected in 2016 by means of a standardized questionnaire. This instrument was administered by face-to-face interviews, at participants households, by trained interviewers. The participants should sign a consent form if they agree to participate in the study. More methodological details of the research can be found elsewhere ${ }^{13}$.

With regards to the socioeconomic evaluation, we used the levels of education (in complete 
years in school); family income in the previous month (which was divided into quartiles); and an assets index, that was generated through a principal component analysis (eigenvalue $=3.3$; explainability of 30\%), considering 11 items of home characteristics or home goods, and further divided into quartiles.

We considered the following indicators : household being registered in the FHS program; a community health worker visit in the previous 12 months; having a health insurance plan; medical consultation in the previous 12 months; dental consultation in the previous six months; dietary counseling in the previous year ${ }^{14}$; class with a physical education professional in the previous three months ${ }^{15}$; flu vaccine in the previous 12 months; mammography exam and cytopathological exams (for women); and prostate exam (for men).

The mammography target population included women aged 50 to 69 years old and prevalence criteria was at least one exam in the previous two years, according to the Brazilian Ministry of Health ${ }^{16}$. The cytopathological exam was targeted to women aged 25 to 64 years old and the prevalence criteria consisted of at least one exam in the previous three years, according to the Brazilian National Institute of Cancer ${ }^{17}$. Prostate exam was targeted to men aged 45 years old or more, according to the Urological Society of Brazil ${ }^{18}$, and considered at least one exam in the life course. All indicators were coded as binary (yes/no) variables.

For statistical analysis, the sample was first described presenting absolute and relative frequencies and Confidence Interval 95\% (95\%CI). For all analysis, the indicators were divided in three groups: a) Health services (FHS registration; a community health worker visit in the previous 12 months; having a health insurance plan); b) having contact with health professionals (medical and dental consultation; dietary counseling and participation in class with a physical education professional); and c) specific health interventions (flu vaccine, mammography exam and cytophatological exam for women; and prostate exam for men). Secondly, equiplots were presented to show inequality in prevalence of indicators. Theses graphs present the prevalence in each subgroup of population and thus the gaps between these groups and inequality structure may be easily visualized $^{19}$. We also estimate complex measures of inequality; the Slope Index (SII) as measure of absolute inequality, and the Concentration Index (CIX) as a measure to relative inequality. SII is a complex measure for ordinal dimensions of in- equality that vary from -100 to 100 with 0 representing equity. Positive values indicate higher prevalence in richer groups and negative values in poorer groups. SII is interpreted in percentage points. CIX indicate if the prevalence of indicator is concentrated and varies from -100 to 100 with 0 representing equity. Positive values indicate concentration of indicator in richer groups and negative values in poorer groups ${ }^{19}$. Although we carried out the main analysis with wealth index quartiles, we also present supplementary material containing same analysis with family income and education. Supplementary material includes prevalence of each indicator for each dimension of inequality and values of SII and CIX. Chart 1 shows detailed definition for indicators, stratifiers and inequalities measures. The analyses were performed in Stata 15.1, considering the sample design effect.

\section{Results}

Out of 1,429 eligible individuals, 1,300 were interviewed, corresponding to $91 \%$ of response-rate. The mean age was 46 years (standard deviation [SD] = 17); the median of schooling level was 11 years (interquartile interval [IQ] $=6$ to 13 ); the median of monthly income per capita was roughly U\$ 250 (IQ = 150 to 440). Regarding the dependent variables, $16.1 \%$ of the participants reported having had a class with a physical education professional in the last three months and $80.0 \%$ reported at least one medical consultation in the previous year (see TS1, available from: https://doi.org/10.48331/scielodata.XT3UHH.

Figure 1 presents proportion of participants who are registered at the FHS, received a visit of community health agents and those covered by private health insurance according to wealth index. While the prevalence of FHS registration and community health agent visits were around 40 and 25 percentage points higher among the poorest compared to the richest group, private health insurance presents an inverse pattern. This indicator was around 40 percentage points higher among those participants belonging to the $25 \%$ richest group, compared to the $25 \%$ poorest.

Having contact with health professionals according to the wealth index was presented in Figure 2. For all these indicators, the richest group presented the highest prevalence. The indicators medical consultation, with a relatively high prevalence in all groups, and dietary counseling (with low prevalence in all groups) presented lower levels of inequality (Figure 2). 
Chart 1. Indicators, stratifiers and inequality measure definitions.

\begin{tabular}{|c|c|c|c|}
\hline \multirow{2}{*}{\begin{tabular}{l}
\multicolumn{1}{c}{ Indicators } \\
Health services \\
characteristics
\end{tabular}} & \multicolumn{3}{|c|}{ Definition } \\
\hline & $\begin{array}{l}\text { Family Health } \\
\text { Strategy } \\
\text { registration }\end{array}$ & $\begin{array}{l}\text { Household being registered in the } \\
\text { Family Health Strategy program }\end{array}$ & $\begin{array}{l}\text { Is your household registered in the } \\
\text { Family Health Strategy? }\end{array}$ \\
\hline & $\begin{array}{l}\text { Visit of } \\
\text { community health } \\
\text { agent }\end{array}$ & $\begin{array}{l}\text { Receive a visit of a community } \\
\text { health worker in the previous } 12 \\
\text { months }\end{array}$ & $\begin{array}{l}\text { Have you received a visit from } \\
\text { a community health agent or a } \\
\text { member of the Family Health } \\
\text { team since last year? }\end{array}$ \\
\hline & $\begin{array}{l}\text { Private health } \\
\text { insurance }\end{array}$ & Private health insurance & Do you have a private health plan? \\
\hline \multirow{4}{*}{$\begin{array}{l}\text { Contact } \\
\text { with health } \\
\text { professional }\end{array}$} & $\begin{array}{l}\text { Dental } \\
\text { consultation }\end{array}$ & $\begin{array}{l}\text { Having a dentist consultation in } \\
\text { the last six months }\end{array}$ & $\begin{array}{l}\text { When was the last time you went } \\
\text { to the dentist? }\end{array}$ \\
\hline & $\begin{array}{l}\text { Medical } \\
\text { consultation }\end{array}$ & $\begin{array}{l}\text { Having a medical consultation in } \\
\text { the last } 12 \text { months }\end{array}$ & $\begin{array}{l}\text { When was the last time you saw a } \\
\text { physician? }\end{array}$ \\
\hline & $\begin{array}{l}\text { Dietary } \\
\text { counselling }\end{array}$ & $\begin{array}{l}\text { Having a dietary counseling in } \\
\text { the previous year }\end{array}$ & $\begin{array}{l}\text { Have you received any } \\
\text { recommendations on eating habits } \\
\text { since last year? }\end{array}$ \\
\hline & $\begin{array}{l}\text { Class with } \\
\text { physical education } \\
\text { professional }\end{array}$ & $\begin{array}{l}\text { Having class with physical } \\
\text { educator in the last three months }\end{array}$ & $\begin{array}{l}\text { Have you had a class with a } \\
\text { physical education professional in } \\
\text { the previous three months? }\end{array}$ \\
\hline \multirow[t]{4}{*}{$\begin{array}{l}\text { Screening and } \\
\text { vaccine }\end{array}$} & $\begin{array}{l}\text { Cytopathologic } \\
\text { exam }\end{array}$ & $\begin{array}{l}\text { At least one cytopathologic exam } \\
\text { in the previous three years (for } \\
\text { women aged } 25 \text { to } 64 \text { years old) }\end{array}$ & $\begin{array}{l}\text { Have you ever done a uterine } \\
\text { cancer screening? } \\
\text { How long ago? }\end{array}$ \\
\hline & Flu vaccine & $\begin{array}{l}\text { Flu vaccine in the previous } 12 \\
\text { months }\end{array}$ & $\begin{array}{l}\text { Have you taken the flu vaccine } \\
\text { shot this year? Did you take it last } \\
\text { year? }\end{array}$ \\
\hline & $\begin{array}{l}\text { Mammography } \\
\text { exam }\end{array}$ & $\begin{array}{l}\text { At least one mammography exam } \\
\text { in the previous two years (for } \\
\text { women aged } 50 \text { to } 69 \text { years old) }\end{array}$ & $\begin{array}{l}\text { Have you ever done a } \\
\text { mammogram? } \\
\text { How long ago? }\end{array}$ \\
\hline & Prostate exam & $\begin{array}{l}\text { At least one prostate exam at any } \\
\text { time (for men aged } 45 \text { years old } \\
\text { or more) }\end{array}$ & $\begin{array}{l}\text { O Sr. já fez exame de próstata, } \\
\text { toque retal ou PSA? } \\
\text { Have you ever done a prostate } \\
\text { exam? }\end{array}$ \\
\hline Stratifier & \multicolumn{3}{|c|}{ Definition } \\
\hline Familiar income & \multicolumn{3}{|c|}{$\begin{array}{l}\text { Amount received by all family members in the previous month divided in quartiles. First } \\
\text { quartile represents the poorest group and the fourth, the richest }\end{array}$} \\
\hline Wealth index & \multicolumn{3}{|c|}{$\begin{array}{l}\text { Take in account characteristics from household (source of drinking water, number of } \\
\text { dormitories and number of toilets) and a list of assets (TV, computer, car, internet, } \\
\text { telephone, etc). A principal component analysis was carried out and the first component } \\
\text { resulting was divided into quartiles. First quartile represents the poorest group and the } \\
\text { fourth, the richest }\end{array}$} \\
\hline Education & \multicolumn{3}{|c|}{ Completed years of scholarship } \\
\hline
\end{tabular}

Source: Authors.

The prevalence of medical consultation, dental consultation, dietary counseling, and class with a physical education professional were 5, 25, 10 and 20 percentage points higher in the richest group, compared to the poorest group, respectively.

Figure 3 shows screening exams (cytopathological exam, prostate exam, mammography) and flu vaccine. The richest present higher prevalence for all indicators in this groups. For cytopathological, mammography, and flu vaccine, the prevalence was around 9-15 percentage point higher in the richest group. Large inequalities were observed in the prostate exam for men (prevalence around 30 percentage points higher in the richest group). 


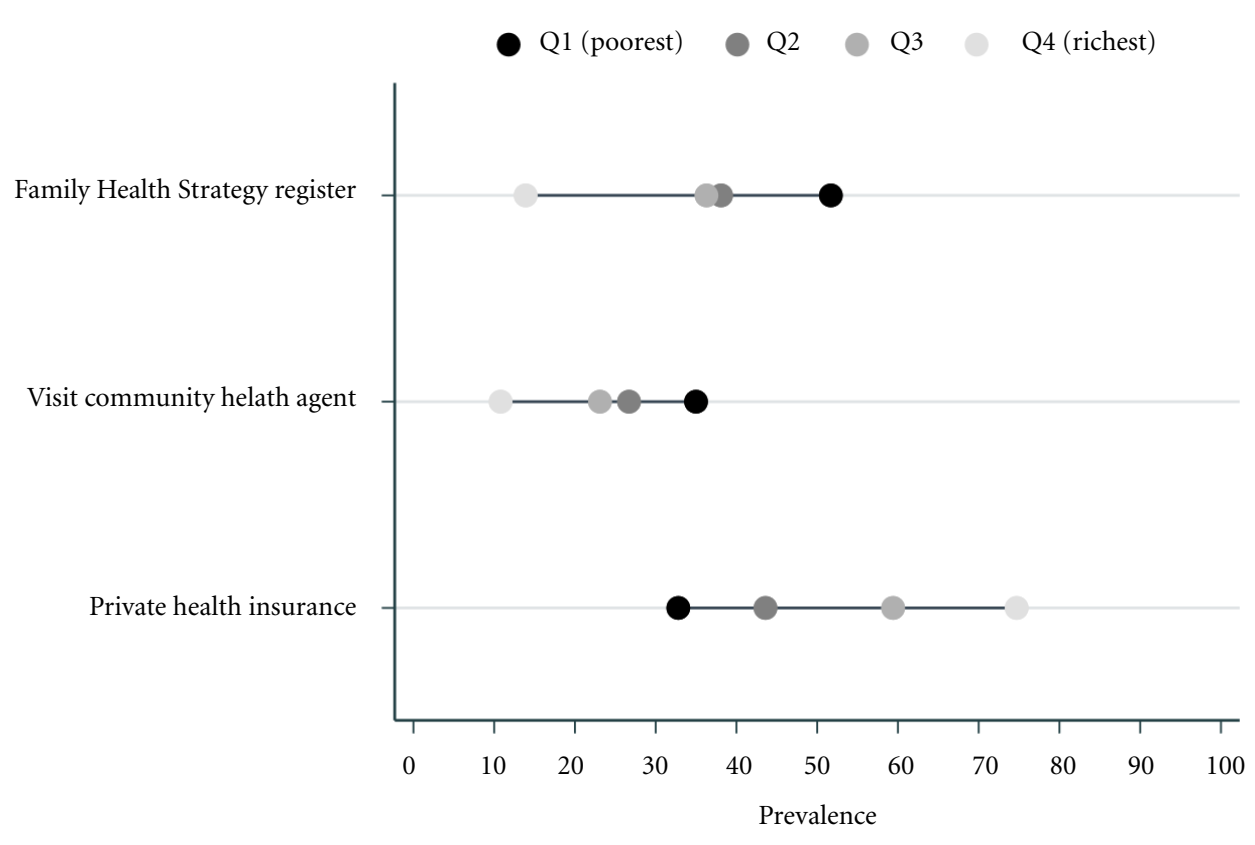

Figure 1. Health services characteristics according to wealth index in adults from Rio Grande/Brazil. Source: Authors.

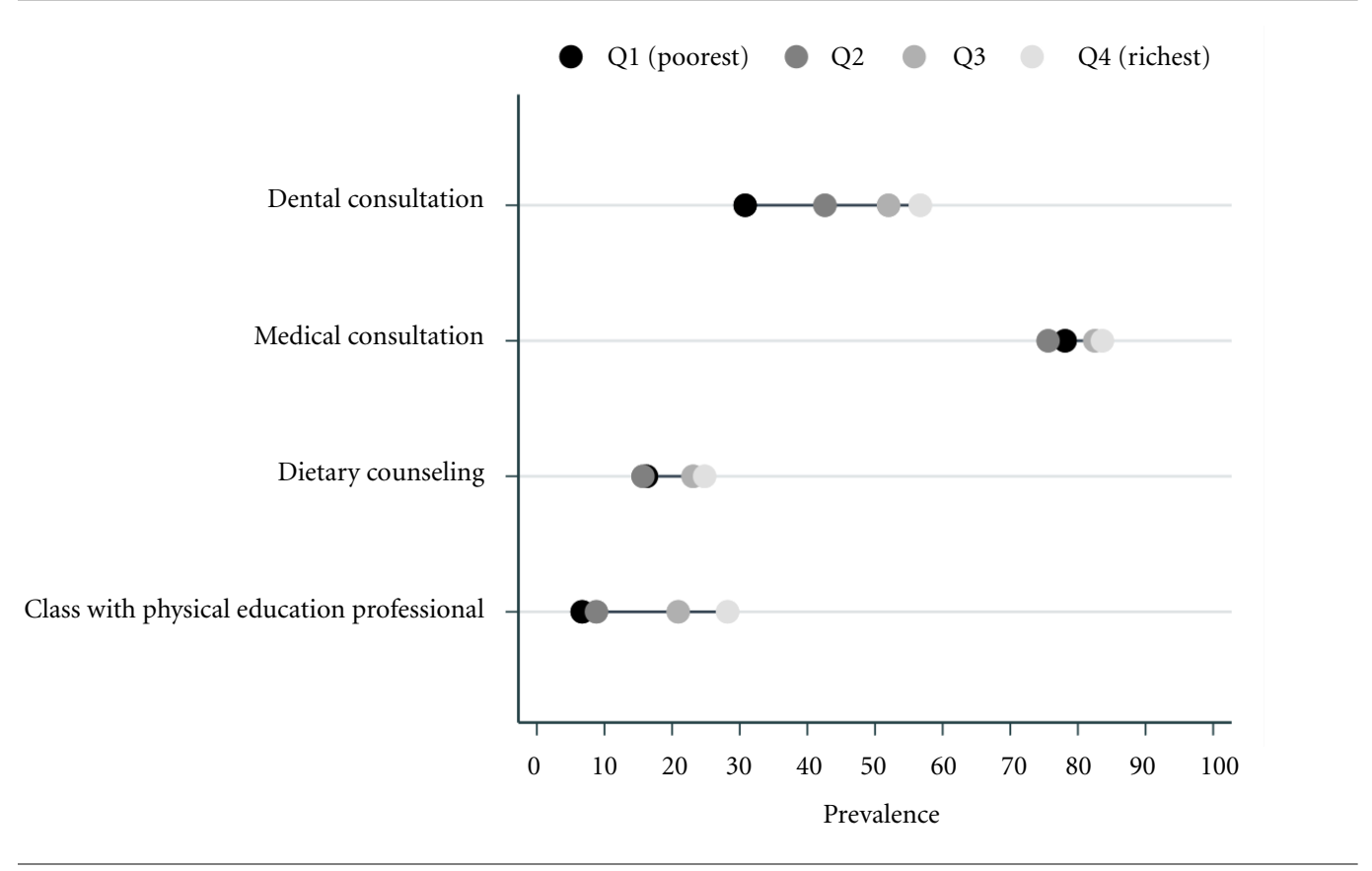

Figure 2. Contact with health professional according to wealth index in adults from Rio Grande/Brazil. Source: Authors. 


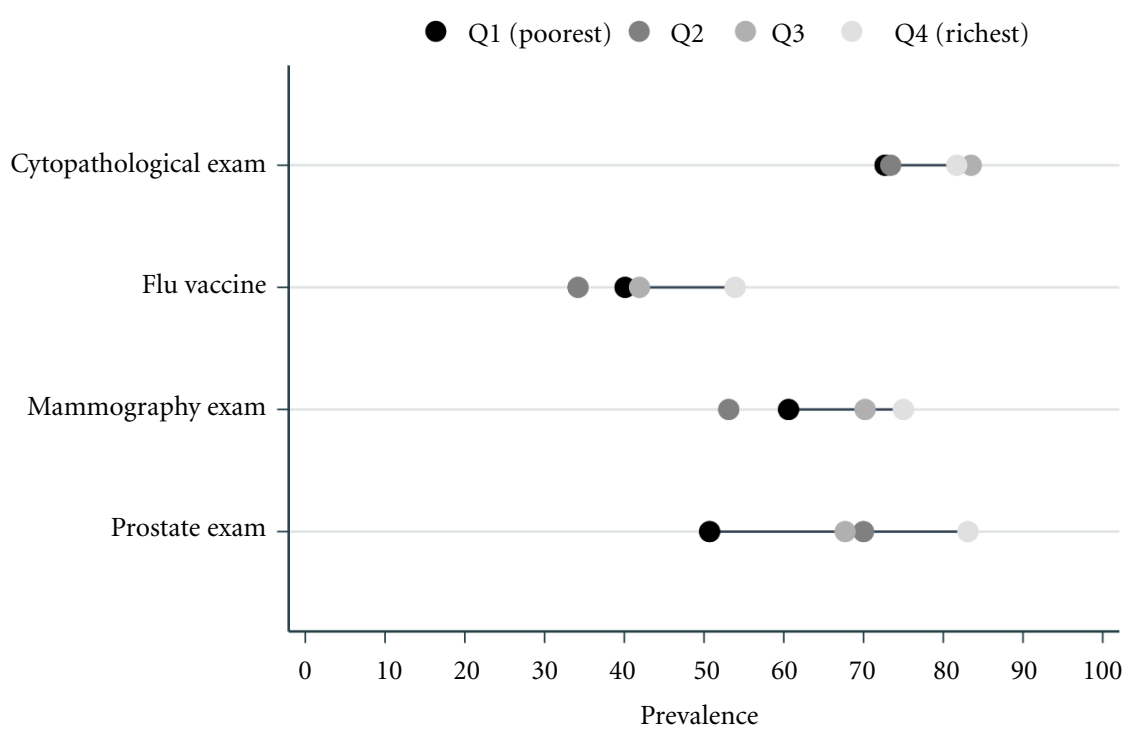

Figure 3. Screening and vaccine according to wealth index in adults from Rio Grande/Brazil.

Source: Authors.

Supplementary Figures (FS1-FS6, available from: https://doi.org/10.48331/scielodata. $\mathrm{XT} 3 \mathrm{UHH}$ ) show prevalence of all indicators according to quartiles of family income and education. The pattern was similar to wealth index for all indicators except to flu vaccine, in which the group with lower education level presented a higher level of vaccination.

Figure 4 shows the relationship between absolute (slope index) and relative (concentration index) inequality, presenting a summary of findings, as well as comparing absolute and relative indices of inequality. There are only two indicators (FHS registration and community health agent visit) presenting higher prevalence among the poorest. The most unequal indicators based on absolute inequality include private health insurance, prostate exam and, dental consultation. Participating in classes with physical education professionals was the most unequal indicator based on the relative inequality measure.

\section{Discussion}

Inequalities in the indicators related to health services, contact with health professionals, screening, and flu vaccination were presented using three different socioeconomic dimensions of inequality in a medium size Southern city of
Brazil. For the majority of the indicators prorich patterns were identified, in which the richest group presented higher prevalence compared to the poorer groups. Having contact with physical education professionals was the indicator with higher relative inequality (CIX), while private health insurance presented the highest absolute inequality (SII). Households covered by the FHS and receiving a community health agent visit were the only two assessed indicators which presented a pro-poor pattern.

To explore inequalities in health service in medium sized cities and non-capitals is a relevant exploration approach. Vast urban centers may accumulate opportunities and jobs but also risks to health and inequalities ${ }^{20}$. While large cities concentrate inequalities, Brazil is a country with huge cultural diversity and with important differences in city structures in health services. A recent study has shown that, for example the coverage of Family Strategy program in the country may vary reaching $64.7 \%$ in the Northeast while in the Southeast is only $46 \%{ }^{21}$. The authors also highlighted the differences between coverage in capitals and interior-cities. In the state of Rio Grande do Sul, the program coverage was $49.5 \%$ and in the state capital (Porto Alegre), 52.2\% These differences in coverage of the program may reflect other characteristics of access to health care in the country. In addition, another 


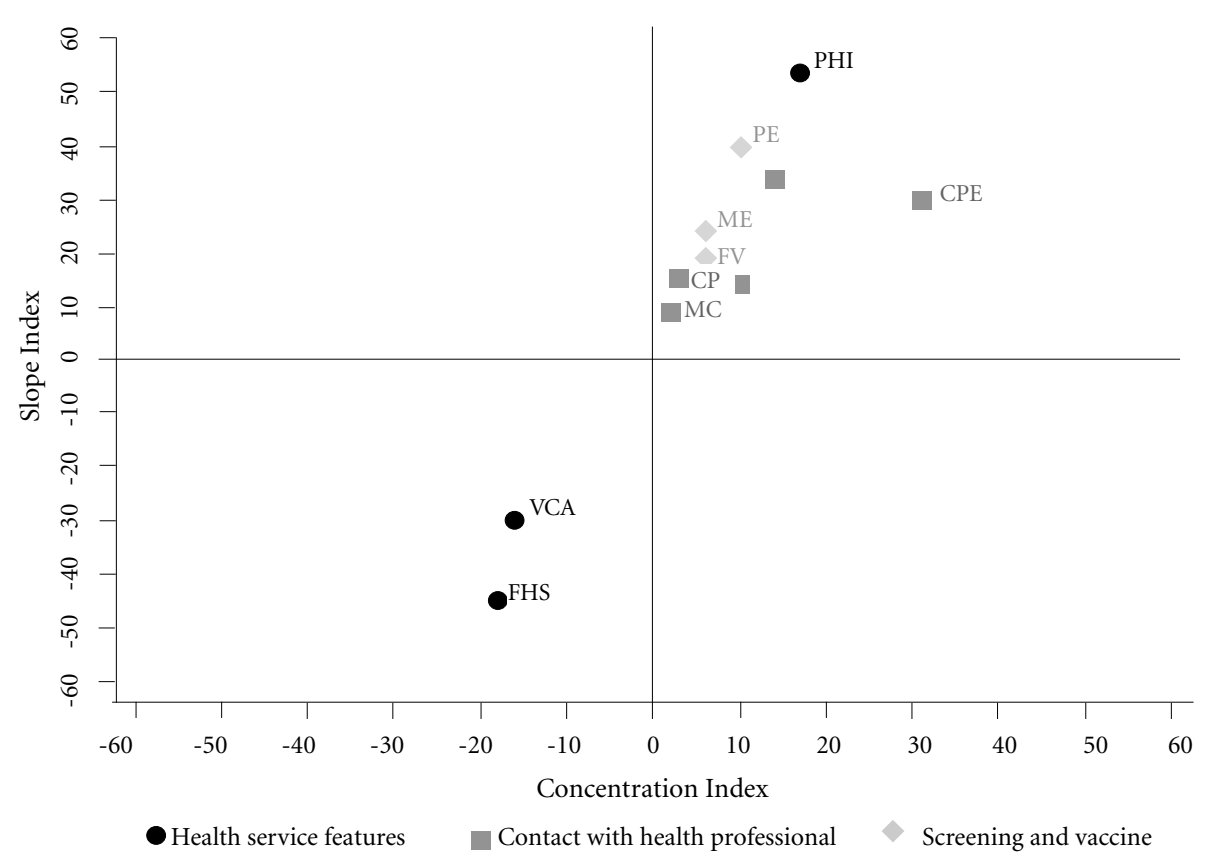

Figure 4. Relationship between slope index and relative index for health services features, contact with health professional, screening and vaccine in adults from Rio Grande/Brazil.

FHS: Family Health Strategy registration; VCA: visit of community health agent; PHI: private health insurance; DeC: dental consultation; MC: medical consultation; DiC: dietary counseling; CPE: class with physical education professional; CP: cytopathological exam; FV: flu vaccine; MM: mammography; PE: prostate exam.

Source: Authors.

study found that human development index for income and longevity of cities is positively associated with the utilization of dental services ${ }^{22}$. Thus, the exploration of health care inequalities in medium and small sized cities is relevant to understand the country as a whole.

In addition to inequality measures, it is also relevant to highlight the lower prevalence for some indicators. Prevalence for FHS registration, community health agent visit, dental consultation, dietary counseling, class with a physical education professional, and flu vaccination did not reach $50 \%$ of the population. The fact these indicators were not close to $50 \%$ is a public health problem to be tackled as the overall prevalence is not high at all. By observing these indicators according to wealth quartiles, we noticed a prevalence of less than $10 \%$ for consultation with physical educators and of only $30 \%$ for dental consultation in the poorest group. The focus on underprivileged groups is likely to be a sound strategy to improve overall prevalence $e^{2,19,23}$.

On the other hand, households with FHS registration and a community health agent's visit were the indicators with higher prevalence among the poorest group. This finding was expected because this program, created in 1994 in Brazil, aimed to improve health care for low-income families ${ }^{24}$. Neves et al. showed that FHS prevalence increased in most parts of Brazil's federative units in the period from 2006 to $2016^{25}$. However, one of the challenges of the strategy nowadays is expanding to populations other than the poorest since it does not reach the middle-upper income families ${ }^{24}$. Instead of a problem, it contributes to the equity of the system. However, if, on the one hand, the greater use of public services for the population with greater social vulnerability shows a tendency towards equity, on the other hand, FHS remains considered by some as "medicine for the poor"26. Some authors also refer to a selective universalization process, focusing on primary care services for the most vulnerable groups and specialized care for the richest, reinforcing a class character associated with the concept of primary health care ${ }^{27,28}$. The historic lack of public investment in the Brazilian Unified Health System - public expenditure lower than other similar international health 
systems - and the recent austerity measures have limited the strengthening and expansion of FHS as well as compromising even further the provision of more complex health care, impacting the integrality of the system ${ }^{29}$.

The most significant inequalities were observed among the indicators of participation in activities with a physical education professional and private health insurance ownership. The latter is easy to understand, as it is directly related to individuals' purchasing power. Furthermore, a literature review has shown that individuals with health insurance are doubled covered by public and private services using the Brazilian Unified Health System when insurances do not cover the type of service required or use hospitals financed by the public sector ${ }^{30}$. The indicator consulting a physical education professional tends to present a much lower prevalence among the poorest groups, even with the recent increase in the access to this professional by the public health system due to its inclusion in some policies of the Brazilian Unified Health System. Another study carried out in the same municipality found that only $16 \%$ of the adult and the elderly had contact with physical education professionals in the last three months. The authors stressed the non-democratic access to these professionals, being a privilege of few population groups, only those with higher education and wealth index ${ }^{15}$. Although physical activity may be performed in other situations or even without a professional, the availability in public sectors is still scarce. For the most part, the individuals need to pay for this service resulting in a barrier to the poorest group ${ }^{31}$.

Another indicator that demonstrated significant inequality in favor of the richest was dental consultation. The Brazilian government implemented the National Oral Health Policy (PNSB) to reduce inequities in oral health in 2004, expanding dental care in the Unified Health Sys$\mathrm{tem}^{32}$. However, it does not seem to have contributed significantly to reducing inequity in access in the studied municipality. The use of this service network enabled the user to provide more comprehensive care, but studies still report low supply and difficulty in accessing this service ${ }^{33,34}$. Inequalities in the use of oral health services are identified even among public service users at different assistance levels. A Brazilian study on the use of public services showed a focus on primary care for the poorest and specialized care for the richest, who possibly have more power to break access barriers $^{33}$.

Socioeconomic conditions seem to have a direct relationship with health indicators. In this sense, the "The Inverse Care Law", published in 1971, is a persistent scenario mainly in low- and middle-income settings. The Inverse Care Law emphasizes that the ones who are in most need for healthcare, are exactly those less likely to receive it: the poorest and most vulnerable population ${ }^{35}$. A study in a nearby city investigated inequalities in access and quality of health care services. According to social class and education, the study did not find significant differences in the use of health care services. On the other hand, waiting periods of 5 or more days for assistance and waiting time in line equal to or greater than 1 hour were both more frequent in lower social positions and lower education groups ${ }^{36}$. This fact may help to understand that sometimes the quality of the services may be more affected than the access depending on the social position. Still, Brazil's current austerity policies freezing Brazilian Unified Health System funding have caused increased private health spending by families, accentuating inequalities ${ }^{37}$. Monitoring of these inequalities is even more relevant in this scenario.

Our study has shown the relationship between absolute and relative measures. We have identified differences in more unequal indicators using absolute and relative measures. None of the measures is better than the other, and both present advantages and limitations. Thus, it is important to show both measures to demonstrate the entire scenario of inequality. Considering the different limitations of inequality measures, some authors recommend using more than one measure, and preferably at least one absolute and one relative measure ${ }^{38}$. Highlighting this statement, we also found in this study that the most unequal indicators are different when using relative or absolute measures. For example, in this study, the prevalence of having a private insurance plan was 33\% in the poorest group and 75\% in the richest. The prevalence in the poorest and richest groups was $7 \%$ and $28 \%$ for classes with physical education professionals, respectively. Although private health insurances have a higher prevalence in the richest group in absolute terms (percentage points), we can see a very relevant relative difference for classes with physical education professionals because the prevalence is small for all groups in this indicator. In mathematic terms, the measures are different, and evaluate both is very important because an indicator not considered as a priority by one measure may be by another.

Another relevant point in this study is the use of different stratifiers for inequalities. Although family income, wealth index, and education may reflect the same idea, they also present different 
mechanisms for inequalities ${ }^{39}$. For example, education may be related to information, income to amount of family resources and wealth index to living standard $s^{39,40}$. In our study, for most findings, the inequalities were consistent across the stratifier groups confirming the patterns for different dimensions of inequality.

We would like to highlight that the results of this study represent the reality of a medium-sized city located in the Southern region of Brazil, and we may extrapolate these findings to other cities in the region. The South and Southeast regions of Brazil are known for having greater coverage of health services, better indicators, and lower inequalities in health than other regions of the country ${ }^{4}$. Therefore, we assume that in other places, inequality in access to health services, as evidenced by this study, might be even more severe.

We should consider a few limitations of this study. All information was self-reported, and the analysed outcomes required different recall peri- ods from respondents, which may have affected each outcome differently. Additionally, we did not ask the reasons for not seeking health services from those who reported not doing so. On the other hand, it is also worth noting that this is a population-based study, rare in small cities, that investigated several outcomes and three different socioeconomic indicators as dimensions of inequality.

In general, we observed a low prevalence/coverage for indicators related to health service access. Besides, inequalities were identified for the vast majority of health indicators with a pro-rich pattern. Such inequalities must be considered to improve coverage, mainly in the most vulnerable groups of society. Strategic programs created by the government have been collaborating to improve health assistance in the most impoverished communities. However, this assistance has been restricted to this group, not reaching a larger part of the society.

\section{Collaborations}

SC Dumith and I Crochemore-Silva conceived and designed the analysis; SC Dumith collected the data; A Wendt and LP Marmitt performed the analysis. A Wendt, LP Marmitt, SC Dumith, I Crochemore-Silva and BP Nunes wrote the paper, carried a critical review, and approved the final version.

\section{References}

1. Victora CG, Barreto ML, Leal MC, Monteiro CA, Schmidt MI, Paim JS, Bastos FIPM, Almeida CM, Bahia L, Travassos CMR, Reichenheim M, Barros FC. Health conditions and health-policy innovations in Brazil: the way forward. Lancet 2011; 377(9782):2042-2053.

2. Pan American Health Organization (PAHO). Health in the Americas. PAHO; 2012.

3. Barata RB. Como e por que as desigualdades sociais fazem mal à saúde?. Rio de Janeiro: Editora Fiocruz; 2012.

4. Albuquerque MV, Viana ALA, Lima LD, Ferreira MP, Fusaro ER, Iozzi FL. Desigualdades regionais na saúde: mudanças observadas no Brasil de 2000 a 2016. Cien Saude Colet 2017; 22(4):1055-1064.

5. Barreto ML. Desigualdades em saúde: uma perspectiva global. Cien Saude Colet 2017; 22(7):2097-2108.

6. Paim J, Travassos C, Almeida C, Bahia L, Macinko J. The Brazilian health system: history, advances, and challenges. Lancet 2011; 377(9779):1778-1797.

7. Brasil. Ministério da Saúde (MS), Departamento de Atenção Básica. Guia prático do programa da Saúde da Família. Brasília: MS; 2011.

8. Macinko J, Lima-Costa MF. Horizontal equity in health care utilization in Brazil, 1998-2008. Int J Equity Health 2012; 11:33.

9. Boccolini CS, Souza Junior PR. Inequities in healthcare utilization: results of the Brazilian National Health Survey, 2013. Int J Equity Health 2016;15(1):150. 
10. Franca GV, Restrepo-Mendez MC, Maia MF, Victora CG, Barros, AJD. Coverage and equity in reproductive and maternal health interventions in Brazil: impressive progress following the implementation of the Unified Health System. Int J Equity Health 2016; 15(1):149.

11. Hosseinpoor AR, Bergen N, Barros AJD, Wong KLM, Boerma T, Victora CG. Monitoring subnational regional inequalities in health: measurement approaches and challenges. Int J Equity Health 2016; 15:18.

12. GBD 2016 Healthcare Access and Quality Collaborators. Measuring performance on the Healthcare Access and Quality Index for 195 countries and territories and selected subnational locations: a systematic analysis from the Global Burden of Disease Study 2016. Lancet 2018; 391(10136):2236-2271.

13. Dumith SC, Paulitsch RG, Carpena MX, Muraro MFR, Simões MO, Machado KP, Dias MS, Kretschmer AC, Oliz MM, Pontes, LS, Susin, LRO. Planejamento e execução de um inquérito populacional de saúde por meio de consórcio de pesquisa multidisciplinar Sci Med 2018; 28(3):ID30407.

14. Simões MO, Dumith SC, Gonçalves CV. Recebimento de aconselhamento nutricional por adultos e idosos em um município do Sul do Brasil: estudo de base populacional. Rev Bras Epidemiol 2019; 22:e190060.

15. Oliz MM, Dumith SC, Knuth AG. Use of physical education services by adults and the elderly in extreme south of Brazil: a population-based study. Cien Saude Colet 2020; 25(2):541-52.

16. Instituto Nacional de Câncer Jose Alencar Gomes da Silva (INCA). Diretrizes para a detecção precoce do câncer de mama no Brasil. Rio de Janeiro: INCA; 2015.

17. Instituto Nacional de Câncer Jose Alencar Gomes da Silva (INCA). Diretrizes brasileiras para o rastreamento do câncer do colo do útero. Rio de Janeiro: INCA; 2016.

18. Sociedade Brasileira de Urologia. Nota Oficial 2017: rastreamento do câncer de próstata 2017 [Internet]. 2017. [cited 2020 Mar 10]. Available from: https://portaldaurologia.org.br/noticias/saiba-mais-sobre-psa-etoque-no-cancer-de-prostata/

19. World Health Organization (WHO). Handbook on health inequality monitoring with a special focus on low and middle-income countries. Geneva: WHO; 2013.

20. World Health Organization (WHO). Hidden cities: unmasking and overcoming health inequalities in urban settings. Geneva: WHO; 2010.

21. Malta DC, Santos MAS, Stopa SR, Vieira JEB, Melo EA, Reis AAC. A Cobertura da Estratégia de Saúde da Família (ESF) no Brasil, segundo a Pesquisa Nacional de Saúde, 2013. Cien Saude Colet 2016; 21(2):327-38.

22. Vieira JMR, Rebelo MAB, Martins NMO, Gomes JFF, Vettore MV. Contextual and individual determinants of non-utilization of dental services among Brazilian adults. J Public Health Dent 2019; 79(1):60-70.

23. Victora CG, Joseph G, Silva ICM, Maia FS, Vaughan JP, Barros FC, Barros AJD. The inverse equity hypothesis: analyses of institutional deliveries in 286 national surveys. Am J Public Health 2018; 108(4):464-71.

24. The Commonwealth Fund. Brazil's Family Health Strategy: using community health care workers to provide primary care 2016. Commonwealth Fund pub 2016; 40. [cited 2020 Mar 10]. Available from: https:// www.commonwealthfund.org/publications/case-study/2016/dec/brazils-family-health-strategy-usingcommunity-health-care-workers
25. Neves RG, Flores TR, Duro SMS, Nunes BP. Tendência temporal da cobertura da Estratégia Saúde da Família no Brasil, regiões e Unidades da Federação, 20062016. Epidemiol Serv Saude 2018; 27(3):e201717.

26. Paim JS. Equidade e reforma em sistemas de serviços de saúde: o caso do SUS. Saude Soc 2006; 5:34-46.

27. Giovanella L. Atenção básica ou atenção primária à saúde? Cad Saude Publica 2018; 34(8):e00029818.

28. Cecilio LCO, Reis AAC. Apontamentos sobre os desafios (ainda) atuais da atenção básica à saúde. Cad Saude Publica 2018;34(8):e00056917.

29. Castro MC, Massuda A, Almeida G, Menezes-Filho NA, Andrade MV, Noronha KVMS, Rocha R, Macinko J, Hone T, Tasca R, Giovanella L, Malik AM, Werneck H, Fachini LA, Atun R. Brazil's unified health system: the first 30 years and prospects for the future. Lancet 2019; 394(10195):345-356.

30. Fontenelle LF, Sarti TD, Camargo MBJd, Maciel ELN, Barros AJD. Utilization of the Brazilian public health system by privately insured individuals: a literature review. Cad Saude Publica 2019; 35(4):e00004118.

31. Kruger J, Carlson SA, Kohl $3^{\text {rd }} H W$. Fitness facilities for adults: differences in perceived access and usage. Am J Prev Med 2007; 32(6):500-505.

32. Brasil. Ministério da Saúde (MS). Diretrizes da política nacional de saúde bucal. Brasília: MS; 2004.

33. Soares FF, Chaves SC, Cangussu MC. [Local government and public dental health services: an analysis of inequality in use]. Cad Saude Publica 2015; 31(3):586596.

34. Chaves SCL, Cruz DN, Barros SG, Figueiredo AL. Avaliação da oferta e utilização de especialidades odontológicas em serviços públicos de atenção secundária na Bahia, Brasil. Cad Saude Publica 2011; 27(1):143-154.

35. Hart JT. The inverse care law. Lancet 1971; 1(7696):405-412.

36. Nunes BP, Thumé E, Tomasi E, Duro SMS, Fachini LA. Socioeconomic inequalities in the access to and quality of health care services. Rev Saude Publica 2014; 48(6):968-976.

37. Santos IS, Vieira FS. Direito à saúde e austeridade fiscal: o caso brasileiro em perspectiva internacional. Cien Saude Colet 2018; 23(7):2303-2314.

38. Barros AJ, Victora CG. Measuring coverage in MNCH: determining and interpreting inequalities in coverage of maternal, newborn, and child health interventions. PLoS Med 2013;10(5):e1001390.

39. McKay A. Defining and measuring inequality. Briefing Paper 2002; 1. [cited 2020 Nov 30]. Available from: https://www.odi.org/publications/2920-defining-andmeasuring-inequality

40. Shaukat B, Javed SA, Imran W. Wealth Index as substitute to income and consumption: assessment of household poverty determinants using demographic and health survey data. J Poverty 2019: 24-44.

Article submitted 25/08/2020

Approved 18/02/2021

Final version submitted 20/02/2021

Chief editors: Romeu Gomes, Antônio Augusto Moura da Silva 